\title{
Spinal cord injury after the use of ecstasy in a young male
}

\author{
Myrna Elena Kastaneer $^{1} \cdot$ Maria Christina Maijers $^{2} \cdot$ Juan David Martina $^{1}$
}

Received: 21 February 2020 / Revised: 27 March 2020 / Accepted: 27 March 2020

(c) International Spinal Cord Society 2020

\begin{abstract}
Introduction Ecstasy is a commonly used party drug and is the second most popular drug after marijuana among youngsters. Serious health hazards have been described including cardiac diseases, neurological complications, multi-organ failure, and even death. Spinal cord injury/dysfunction (SCI/D) is rarely described as a result of ecstasy ingestion.

Case presentation We present a case of a 19-year-old male patient who was admitted to our rehabilitation center, after developing a T11 AIS B SCI/D following recreational use of ecstasy.

Discussion In our case magnetic resonance imaging was inconclusive due to artifacts caused by metallic rods used for surgical scoliosis treatment in the past. This individual received no surgical or pharmacological treatments; however, it is questionable whether any specific treatments would have been beneficial.

Ecstasy ingestion leads to a serotonin surge and induces microvascular changes. Neurovascular hemorrhage, subarachnoid hemorrhage, de novo aneurysm formation, and subsequent rupture can occur. 5-hydroxytryptamine, which comes from serotonergic terminals, is a very potent vasoconstrictive amine and can thus lead to prolonged vasoconstriction and ischemia. It is most likely that the SCI/D in our case is the result of an ischemic event following the vasoconstrictive effects of ecstasy ingestion. It is important to stress the possible consequences of recreational ecstasy usage and in unexplained SCI/D, one should consider the possibility of drug-related causes.
\end{abstract}

\section{Introduction}

3,4-methylenedioxymethamphetamine (MDMA), commonly referred to as ecstasy, is a frequently used recreational party drug, becoming more popular among young people in the last decade [1]. In the United Kingdom, ecstasy is the second most popular drug after Cannabis among 16-24-year-old individuals. It is the third most popular drug, after Cannabis and Cocaine, for 16-59 years old [2]. The drug is regarded as one of the most significant problem drugs in the world by the United Nations [3]. Ecstasy is structurally related to amphetamine and makes users feel "high." When used there is a disinhibition of social relations; it gives openness of spirit, increased empathy toward other people, increased self-esteem and

\footnotetext{
Myrna Elena Kastaneer

myrna.kastaneer@gmail.com

Rehabilitation Center SGR Group, Willemstad, Curaçao

2 Amsterdam Rehabilitation Research Center I Reade, Amsterdam, The Netherlands
}

self-confidence, euphoria, increased vigilance, improvement of mood, and abolition of fatigue [4].

According to the literature, MDMA acts at the central nervous system in different ways. Its main mechanism of action is an acute and rapid release of 5-hydroxytryptamine (5-HT) from serotonergic terminals; this leads to a $5-\mathrm{HT}_{2 \mathrm{~A}}$ receptor downregulation. The serotonin can lead to serotonin surge-induced microvascular changes. Cases of intracerebral hemorrhage, subarachnoid hemorrhage, de novo aneurysm formation, and its rupture have been described. Furthermore, since 5-HT can also lead to prolonged vasospasm it may cause ischemia [5, 6].

The number of users of ecstasy worldwide is circa 20.5 million as estimated by the United Nations in 2016. The highest prevalence is reported in Asia, followed by Europe and the Americas. For the Caribbean it was estimated that there were 60,000 users of ecstasy [7]. There are no specific numbers available for the use of ecstasy in Curaçao. In 2017, 2\% of Curaçao natives over 18 years of age had used soft drugs in the past year, mostly marijuana. The use of hard drugs, which includes ecstasy, was reported by $0.5 \%$ of the adults. Drug use is more common among men compared with women and most users have a low socioeconomic status [8]. A significant problem on the island is 
the use of drugs by Dutch medical interns, general trainees, and apprentices; $40 \%$ of them use ecstasy or cocaine [9]. In the Netherlands, which has the largest group of ecstasy users in Europe, $20-25 \%$ of people between 20 and 30 years of age have had an experience with ecstasy. Between 2009 and 2017 the Monitor Drug Incidents in the Netherlands registered almost 12,000 incidents related to ecstasy for which medical assistance was needed. This is $\sim 1500$ incidents per year. Most incidents occur during large social events. It is estimated that 1 in 250 users of ecstasy has complications; most occur in young individuals [10].

With the increasing recreational use of ecstasy, the medical complications of its use are more frequently described in the medical literature. Among the mentioned health hazards after recreational use of ecstasy are neurological complications, for example: convulsions, coma, cerebral vasculitis and cerebral vascular accidents. Other health problems described are cardiac arrhythmia, renal problems, rhabdomyolysis, disseminated intravascular coagulation, hyperthermia and even death $[6,11,12]$. BenAbraham et al. described three cases of ecstasy intoxication that required 2-6 days of ICU care; complications included coma, convulsions, necessity of intubation and mechanical ventilation, acute respiratory distress syndrome, rhabdomyolysis, metabolic and lactic acidosis, hyponatremia, hyperthermia, hepatotoxicity and thrombocytopenia [11]. All patients were discharged home with no sequelae.

Goldstein et al. described the first case of severe spinal cord injury/dysfunction (SCI/D) following the use of ecstasy presenting as an acute quadriplegia and respiratory insufficiency [13]. The patient was admitted to the acute care hospital for 3 months, and afterwards spent 3 months at a rehabilitation center. After 6 months of rehabilitation, he was able to walk with complete recovery of the right hemiparesis but with mild residual left hemiparesis. At 1year follow-up no further improvement was noted.

Although many reversible complications have been described, there are also cases described in which patients did not recover fully. It is important to know and understand the risks of the recreational use of ecstasy. We present therefore our case of SCI/D after the use of ecstasy, with irreversible damage.

\section{Case presentation}

A 19-year-old male presented at the emergency room (ER) in Curaçao with rapidly progressive loss of motor function and dysesthesia in both lower extremities. His medical records indicated a history of scoliosis, for which a spinal fusion with rods was performed 3 years earlier. The young man used ecstasy for recreational purposes on the weekends and it was usual for him to develop abdominal pain followed by having defecation after consumption. On the day of presentation on the ER, he had consumed ecstasy and as usual he experienced abdominal pain half an hour later. However, when he had a stool $2 \mathrm{~h}$ after taking the ecstasy, he suddenly experienced back pain and an electrical sensation in both lower extremities. This was followed by a rapid loss of strength in the legs. At the ER, the neurologist described that the patient had a paraplegia with absent vital sensibility and abnormal proprioception below T12. Urine retention of $700 \mathrm{cc}$ was measured and a bladder catheter was placed; patient did not feel the catheter in situ. The initial physical examination at the time was not performed according to the International Standards for the Neurologic Classification of SCI (ISNCSCI). Two days later, doctors of the rehabilitation department did perform the physical examination according to the ISNCSCI and concluded that patient had a T11 AIS B SCI/D. The upper extremities showed no neurological deficits; the legs were completely paralyzed. The individual was able to feel his urinary catheter and had some voluntary anal contraction and deep anal sensation, however, he had no control over his ability to defecate.

At the ER, a conventional X-ray of the spine was performed, which showed an intact position of the spinal rods. The following day a magnetic resonance imaging (MRI) of the whole spine was performed, but due to artifacts caused by the metallic components used for the scoliosis, the images could not be accurately evaluated. The cervical and lumbar/sacral part of the spine which could be evaluated well (C1-T2 and L2-S5) showed no abnormalities. From T2 to L2, the myelum was hardly visible and no definite conclusions could be drawn from these images (Figs. 1 and 2).

Fourteen days after hospital admission, the individual was transferred to the Rehabilitation Center Curaçao.

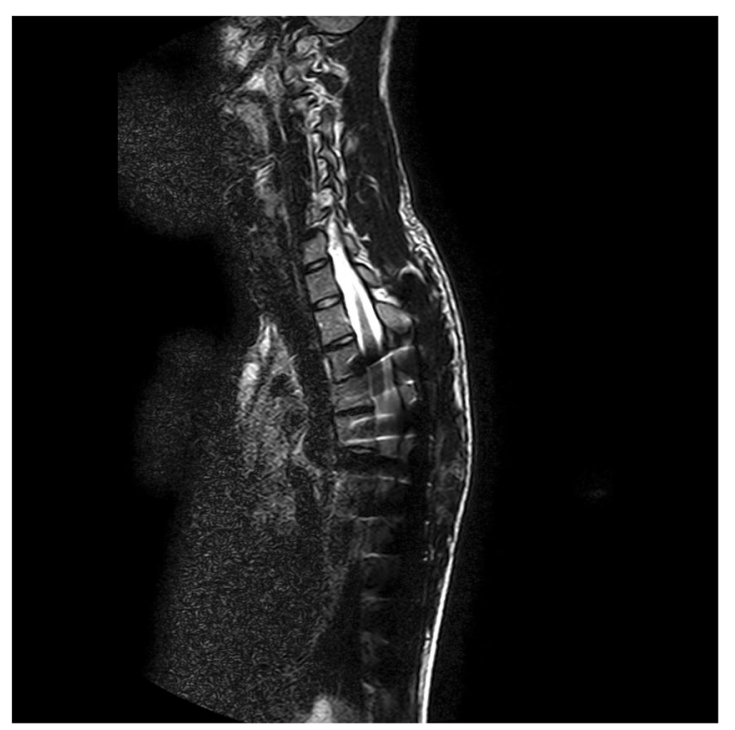

Fig. 1 T2 weighted sagittal MRI images of the cervical and thoracic spine; due to artifacts the myelum cannot be evaluated properly. 


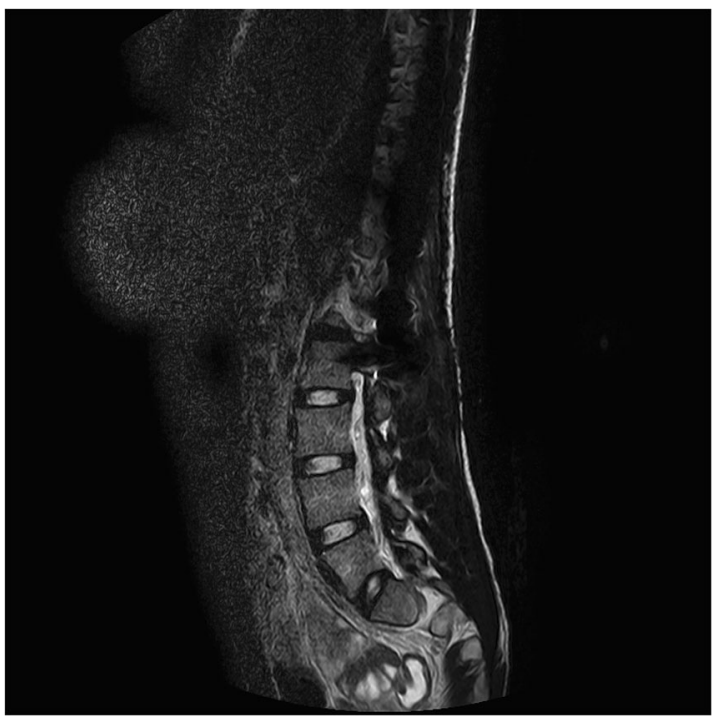

Fig. 2 T2 weighted sagittal MRI images of the thoracic, lumbar, and sacral part of the spine; due to artifacts the myelum cannot be evaluated properly.

During admission he learned to perform activities of daily living from a wheelchair; this included self-catheterization. Defecation was regulated with Bisacodyl $10 \mathrm{mg}$ rectal every other day and Movicolon (Macrogol with electrolytes) daily. After 44 days of inpatient rehabilitation, he was discharged home. In Curaçao, the assessment of a patient's independence in daily living is performed by means of the Functional Independence Measure (FIM) [14] score. The FIM score has a maximum of 126 points, however, in Curaçao a slightly adapted version of the FIM score is used. Since there are barely any stairs in Curaçao, the ability to walk stairs is not scored (not relevant), therefore the maximum score on the FIM is 119. At discharge the individual had an FIM score of 101 out of 119; he was functioning independently from a wheelchair. The reason the FIM score was not maximal was because he was still incontinent for micturition and defecation. The strength in the legs had gradually improved; however, due to severe weakness in the muscles of the hip flexors and knee flexors, he was not able to stand unsupported at discharge. Physical examination showed absent ankle reflexes, neutral foot sole reflexes, and normal anal wink. The bulbocavernosus reflex was not tested. Sensibility level had lowered; from L2 downwards, the sensation for touch and pinprick was altered (lowest intact neurological level was L1); the sensibility was intact in the sacral segments (sacral sparing). At discharge he had a L1 AIS D SCI/D. The individual continued outpatient rehabilitation treatment. Approximately 3 months after developing the SCI/D, the man was seen at the outpatient clinic; examination showed minimal improvement in motor function in the legs, however, this did not lead to a better functional performance. He was still wheelchair bound, incontinent for micturition and defecation and presented sexual dysfunction. During outpatient physical therapy the individual did practice walking with crutches, however, it was not functional enough for walking outside therapy. Six months after onset of the complaints there was no significant improvement in muscle strength, lower urinary tract function, bowel function, or sexual functions. However, with continuation of outpatient rehabilitation treatment further improvement in walking ability was seen; he was able to walk with two crutches. At 3- and 6-month followup the level of the SCI/D was unchanged: L1 AIS D.

A summary of the findings at physical examination and autonomic functions is presented in Table 1.

\section{Discussion}

In this case of a young man with SCI/D due to use of ecstasy, no specific treatment was performed at the hospital. However, it is questionable whether surgical intervention or pharmacological treatment-such as high doses of corticosteroids and intravenous immunoglobulins-would have been beneficial.

Pharmacological treatment of an SCI/D following ingestion of ecstasy has been described by Goldstein et al. [13]. MRI images showed a dilating lesion of the spinal cord, with high T2 signals and mild gadolinium enhancement. Differential diagnoses were a lesion either secondary to acute vascular damage, a demyelinative process such as multiple sclerosis, or acute disseminating encephalomyelitis. Patient was immediately treated with intravenous immunoglobulins and high doses of corticosteroids, but this did not improve his condition. It was only 1 month later that MRI images showed remarkable improvement of the cervical edema, associated with improvement of the paresis. They concluded that the spinal cord edematous lesion may have been caused by severe spinal vasoconstriction and possible necrotizing vasculitis. In our case, neurology and neurosurgery saw no indication for surgical intervention or pharmacological treatment, which is supported by the findings of Goldstein et al. [13].

The MRI machine that was used in our hospital dates from 2003; the authors wonder better images would have been available if the MRI was performed in abroad with a more modern machine. With the construction of a new hospital, a last-generation MRI machine became available on the island. A new MRI was performed 9 months after start of complaints. The thoracic and lumbar part of the spine could again not be evaluated accurately due to artifacts. The diameter of the spinal canal seemed normal; however, a myelopathy or compression of the spinal cord could not be ruled out with certainty.

According to the literature, MDMA acts at the central nervous system in different ways. Its main action is an acute 


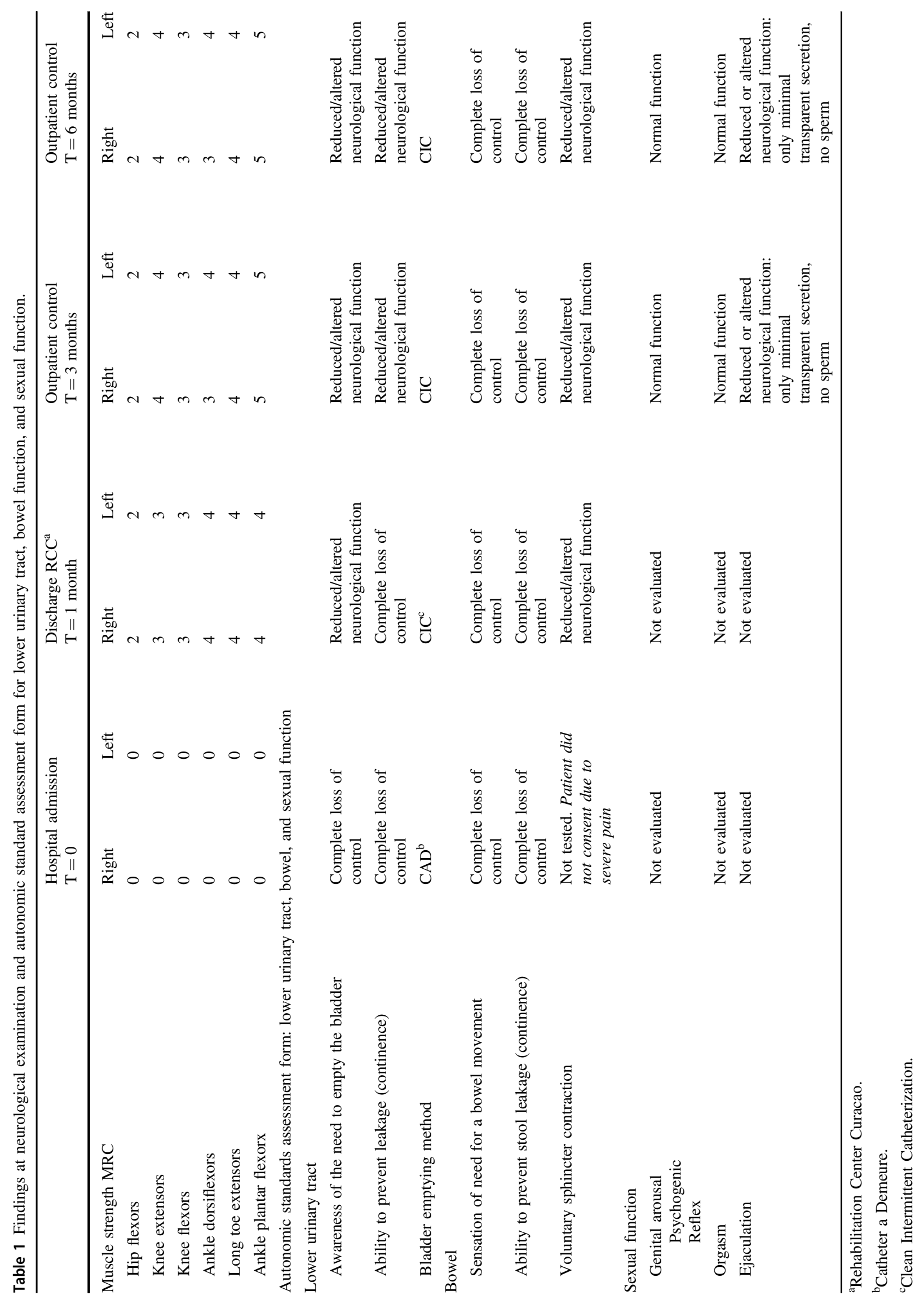


and rapid release of 5-HT from serotonergic terminals, this leads to a $5-\mathrm{HT}_{2 \mathrm{~A}}$ receptor downregulation. This can lead to serotonin surge-induced microvascular changes. Neurovascular inflammation and de novo aneurysm formation can occur. Combined with acute post-consumption blood pressure elevation, it can result in intracerebral hemorrhage, subarachnoid hemorrhage, and rupture of (de novo formed) aneurysms [5]. 5-HT is also a very potent vasoconstrictive amine, therefore it has been suggested that stimulation of 5HT2A receptors may lead to prolonged vasospasm, which causes ischemia [6]. Since MRI imaging was inconclusive due to artifacts, we cannot state the cause of the SCI/D in our patient with absolute certainty. We assume that an ischemic event was responsible for the neurological picture. This assumption is based on the similarities of our case compared with the case described by Goldstein et al. [13].

As SCI/D after ecstasy use is not frequently mentioned in the literature, we feel it is important to stress the possible consequences of recreational use of ecstasy. In unexplained $\mathrm{SCI} / \mathrm{D}$, one should consider the possibility of drug-related causes. This young individual experienced the unexpected, traumatic, and disabling effects of using ecstasy that has changed his life forever with devastating consequences despite a comprehensive rehabilitation program. The authors encourage therefore anyone to abstain from using ecstasy and other related drugs.

Acknowledgements We would like to thank neurosurgeon E. Dos Santos Rubio and radiologist J. Tai who offered their professional opinion on the case and the possibility to perform additional diagnostics in support of our case report.

\section{Compliance with ethical standards}

Conflict of interest The authors declare that they have no conflict of interest.

Publisher's note Springer Nature remains neutral with regard to jurisdictional claims in published maps and institutional affiliations.

\section{References}

1. Palamar JJ, Mauro PM, Han BH, Martins SS. Shifting characteristics of ecstasy users ages 12-34 in the United States, 20072014. Drug Alcohol Depend. 2017;181:20-4.

2. Ecstasy. DrugWise. 2017. https://www.drugwise.org.uk/ecstasy/.

3. Ecstasy is Popular. Drug Advisory Council of Australia. 2012. https://daca.org.au/ecstasy-is-popular/.

4. Moratalla R, Khairnar A, Simola N, Granado N, García-Montes JR, Porceddu PF, et al. Amphetamine-related drugs neurotoxicity in humans and in experimental animals: main mechanisms. Prog Neurobiol. 2017;155:149-70.

5. Johnson J, Patel S, Saraf-Lavi E, Aziz-Sultan MA, Yavagal DR. Posterior spinal artery aneurysm rupture after 'ecstasy' abuse. BMJ Case Rep. 2014;2014:bcr2014011248.

6. Rojas R, Riascos R, Vargas D, Cuellar H, Borne J. Neuroimaging in drug and substance abuse part I: cocaine, cannabis, and ecstasy. Top Magn Reson Imaging. 2005;16:231-8.

7. Annual prevalence of the use of drugs by region and globallyl Statistics and Data. United Nations. 2018. https://dataunodc.un. org/drugs/prevalence_regional\#ecstasy.

8. Verstraeten S, Griffith-Lendering MFH, Pin R. De nationale gezondheidsenquête Curaçao 2017: de belangrijkste resultaten, methode en tabellen, Volksgezondheid Instituut Curaçao (VIC), Willemstad. 2017.

9. Jong Hde. Poster moet drugsgebruik Nederlandse stagiairs op Curaçao tegengaan. NOS. 2016. https://nos.nl/op3/artikel/ 2082983-poster-moet-drugsgebruik-nederlandse-stagiairs-op-Cura çao-tegengaan.html.

10. van Laar M. Kanttekeningen bij legaliseren xtc. Trimbos.nl. Trimbos Instituut. 2018. https://www.trimbos.nl/actueel/blogs/ blog/kanttekeningen-bij-legaliseren-xtc.

11. Ben-Abraham R, Szold O, Rudick V, Weinbroum AA. 'Ecstasy' intoxication: life-threatening manifestations and resuscitative measures in the intensive care setting. Eur $\mathrm{J}$ Emerg Med. 2003;10:309-13.

12. Mende L, Böhm R, Regenthal R, Klein N, Grond S, Radke J. Hyperdynamer Kreislaufstillstand nach Ingestion von Ecstasy. ains - ästhesiologie - Intensivmed · Notfallmedizin - Schmerztherapie. 2005;40:762-5.

13. Goldstein LH, Mordish Y, Abu-Kishak I, Toledano M, Berkovitch M. Acute paralysis following recreational MDMA (ecstasy) use. Clin Toxicol. 2006;44:339-41.

14. Uniform Data System for Medical Rehabilitation. The FIM ${ }^{\circledR}$ instrument: its background, structure, and usefulness. Buffalo: $\mathrm{USD}_{\mathrm{MR}} ; 2012$. 